\title{
Exobiopolymer production of Ophiocordyceps dipterigena BCC 2073: optimization, production in bioreactor and characterization
}

\author{
Kanokarn Kocharin', Pranee Rachathewee1, Jean-Jacques Sanglier² and Wai Prathumpai*1
}

\begin{abstract}
Background: Biopolymers have various applications in medicine, food and petroleum industries. The ascomycetous fungus Ophiocordyceps dipterigena BCC 2073 produces an exobiopolymer, a (1 $\rightarrow 3)-\beta$-D-glucan, in low quantity under screening conditions. Optimization of O. dipterigena BCC 2073 exobiopolymer production using experimental designs, a scale-up in 5 liter bioreactor, analysis of molecular weight at different cultivation times, and levels of induction of interleukin-8 synthesis are described in this study.

Results: In order to improve and certify the productivity of this strain, a sequential approach of 4 steps was followed. The first step was the qualitative selection of the most appropriate carbon and nitrogen sources (general factorial design) and the second step was quantitative optimization of 5 physiological factors (fractional factorial design). The best carbon and nitrogen source was glucose and malt extract respectively. From an initial production of $2.53 \mathrm{~g} \cdot \mathrm{L}^{-1}$, over $13 \mathrm{~g} \cdot \mathrm{L}^{-1}$ could be obtained in flasks under the improved conditions (5-fold increase). The third step was cultivation in a $5 \mathrm{~L}$ bioreactor, which produced a specific growth rate, biomass yield, exobiopolymer yield and exobiopolymer production rate of $0.014 \mathrm{~h}^{-1}, 0.32 \mathrm{~g} \cdot \mathrm{g}^{-1}$ glucose, $2.95 \mathrm{~g} \cdot \mathrm{g}$ biomass $^{-1}\left(1.31 \mathrm{~g} \cdot \mathrm{g}^{-1}\right.$ sugar), and $0.65 \mathrm{~g} .(\mathrm{L} \cdot \mathrm{d})^{-1}$, respectively. A maximum yield of $41.2 \mathrm{~g} \cdot \mathrm{L}^{-1}$ was obtained after $377 \mathrm{~h}$, a dramatic improvement in comparison to the initial production. In the last step, the basic characteristics of the biopolymer were determined. The molecular weight of the polymer was in the range of $6.3 \times 10^{5}-7.7 \times 10^{5} \mathrm{Da}$. The exobiopolymer, at 50 and $100 . \mu \mathrm{g} \cdot \mathrm{mL}^{-1}$, induced synthesis in normal dermal human fibroblasts of 2227 and $3363 \mathrm{pg} \cdot \mathrm{mL}^{-1}$ interleukin-8 respectively.

Conclusions: High exobiopolymer yield produced by O. dipterigena BCC 2073 after optimization by qualitative and quantitative methods is attractive for various applications. It induced high IL-8 production by normal dermal fibroblasts, which makes it promising for application as wound healing material. However, there are still other possible applications for this biopolymer, such as an alternative source of biopolymer substitute for hyaluronic acid, which is costly, as a thickening agent in the cosmetic industry due to its high viscosity property, as a moisturizer, and in encapsulation.
\end{abstract}

\section{Background}

Exopolysaccharides (EPS), synthesized by various microbes growing on different carbon sources, are secreted as slime or jelly-like material [1]. These microbial biopolymers are classified as homopolysaccharides and heteropolysaccharides depending upon their chemical structures. The homo- and heteropolysaccharides are synthesized by single and multi-enzyme systems on either single carbon or

* Correspondence: wai.pra@biotec.or.th

${ }^{1}$ National Center for Genetic Engineering and Biotechnology, National Science and Technology Development Agency, 113 Thailand Science Park, Klong 1, Klong Luang, Pathumthani 12120, Thailand

Full list of author information is available at the end of the article complex carbon sources [2]. Microbes producing extracellular biopolymers include basidiomycetes [3-6], entomopathogenic fungi [7-16] lichenized fungi [17], white rot fungi [18], and bacteria [19]. Examples of homopolysaccharides are scleroglucan from Sclerotium sp. [20], pullulan from Pullularia pullulan [21], curdlan from Alcaligenes faecalis [22], and dextran from Leuconostoc mesenteroides [23]. Heteropolysaccharides include xanthans from Xanthomonas compestris [24] and algenates from Azotobacter vinelandii [25]. Biopolymers produced by ascomycetes have been described from Cordyceps [10,11,13-15] and Paecilomyces [26-28]. 
Exobiopolymers have specific applications in medicine, food and petroleum industries [29] depending on their structures and properties. Exobiopolymers from basidiomycetes are potent anti-tumor and immunomodulating agents [30], and some are used in food and as biocoating materials [31].

Sixteen strains from 15 different genera of fungi have been evaluated for their biopolymer synthesis, and the biological properties of the biopolymer were characterized [7]. Exobiopolymer from Ophiocordyceps dipterigena BCC 2073 is a potent wound dressing material due to its appropriate biological and physiological properties. It is biocompatible, non-cytotoxic and a strong inducer of interleukin-8 (IL-8), a cytokine responsible for enhancing wound healing process $[7,8]$. The exobiopolymer is composed of (1T3)- $\beta$ - $D$-glucan backbone, substituted at $O-6$ with side chains of (1T6)- $\beta$ - $D$-pyranosyl units and contains $1.86 \%$ arabinose, $29.08 \%$ mannose, $25.86 \%$ galactose and $43.05 \%$ glucose [8].

Fermentation processes in submerged culture has proven to be effective for exobiopolymer production, suitable for downstream processes with other fungal strains $[27,28]$. Up to $34.5 \mathrm{~g} \cdot \mathrm{L}^{-1}$ of exobiopolymer was produced using Paecilomyces japonica in a 5-liter bioreactor after optimization of physical conditions [32]. However, the biological properties of $P$. japonica biopolymer were not investigated. The culture conditions, such as aeration, have an influence also on the quality of the compound [33].

Biopolymers dissolved in liquid media increase the apparent viscosity and cause pseudoplastic flow behavior. The oxygen transfer rate also is decreased. As Ophiocordyceps dipterigena BCC 2073 synthesizes only a limited amount of exobiopolymer under the screening conditions, optimization of cultivation conditions was warranted.

We describe here an optimization of $O$. dipterigena BCC 2073 exobiopolymer production using experimental designs, the production in a 5-liter bioreactor, an analysis of molecular weight at different cultivation times, and the level of induction of IL- 8 synthesis by normal dermal fibroblasts.

\section{Results}

Optimization of exobiopolymer production General factorial design (qualitative optimization)

The goal of this experiment was to choose the best carbon and nitrogen sources using a full experimental design. The experimental design and the results are given in Table 1. The models are:

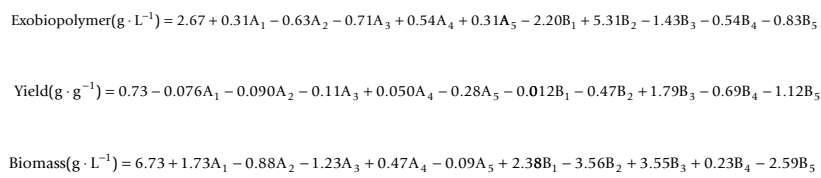

where $\mathrm{A}_{1}=$ glucose, $\mathrm{A}_{2}=$ galactose, $\mathrm{A}_{3}=$ lactose, $\mathrm{A}_{4}=$ mannose, $A_{5}=$ maltose, $B_{1}=$ peptone, $B_{2}=$ malt extract,
$\mathrm{B}_{3}=$ yeast extract, $\mathrm{B}_{4}=$ ammonium dihydrogen phosphate, and $\mathrm{B}_{5}=$ ammonium sulphate.

The effect of each source is significant, except for peptone in the case of yield and for maltose in the case of biomass. Types of carbon source (Table 1 ) showed relatively little influence on biopolymer production, biomass and productivity. The influences are not significantly different. The best carbon source for biopolymer production was glucose, followed by mannose. Variations of production with this series of 5 carbon sources were from 1.56 to 3.30 , corresponding to $111 \%$. Interestingly these two carbon sources also supported the best growth. Variations in biomass were limited, ranging from 5.48 to 8.48, corresponding to $54 \%$. Yields were little influenced, with a minimum of 0.62 and a maximum of 0.78 , or a variation of $25 \%$. As glucose is a component of the biopolymer [8], gave the highest biopolymer production, and is available at a reasonable price, it was selected for use in further experiments.

The quality of nitrogen sources played an important role on all three responses evaluated. Biopolymer production varied from 0.38 (peptone) to 7.9 (malt extract), a multiplication factor of 20 . The best nitrogen source for production was malt extract. Yield varied from 0.04 (peptone) to 2.52 (malt extract), a factor of 43. The highest exobiopolymer yield was achieved with yeast extract (equation 2) with a coefficient of 1.79. Biomass was less influenced by the types of nitrogen, ranging from 3.16 (malt extract) to 10.32 (yeast extract), a factor of 3. Although yeast extract was the best source it gave lower exobiopolymer yields. It also should be noted that the strain showed good growth on ammonium nitrogen sources but with low yields.

Thus, glucose and malt extract were chosen for further experiments involving two-level fractional factorial design in order to determine optimal conditions for exobiopolymer production.

\section{Two-level fractional factorial design (quantitative optimization)}

The influences of 5 quantitative factors (glucose concentration, malt extract concentration, amount of trace element solution, amount of vitamin solution, and temperature) on exobiopolymer production, biomass and yield of $O$. dipterigena BCC 2073 were evaluated in a fractional factorial design at 2 levels (coded -1 and +1 ) together with a center point replication (coded 0) (Table 2).

The results of combination 1 to 16 showed large differences (Table 3). The highest biopolymer yield was reached in medium $8\left(13.2 \mathrm{~g} \cdot \mathrm{L}^{-1}\right)$ and the lowest in medium 13 (4.8 g. $\left.\mathrm{L}^{-1}\right)$, a multiplication factor of 2.6. With regards to biomass production, this varied from 3.1 (medium 9) to 6.6 (medium 16), a multiplication factor of 2.1. The best yield was obtained in medium 9 (3.29) and 
Table 1: Biomass and exobiopolymer production on different carbon and nitrogen sources using Latin square design.

\begin{tabular}{|c|c|c|c|c|}
\hline Carbon source & Nitrogen source & Exobiopolymer $\left(g \cdot \mathrm{L}^{-1}\right)$ & Yield ( $g_{\text {exobiopolymer }} \cdot \mathrm{g}^{-1}$ biomass $)$ & Biomass $\left(\mathbf{g} \cdot \mathrm{L}^{-1}\right)$ \\
\hline \multirow[t]{5}{*}{ galactose } & $\mathrm{NH}_{4} \mathrm{H}_{2} \mathrm{PO}_{4}$ & $1.9 \pm 0.10$ & $0.28 \pm 0$ & $6.7 \pm 0.53$ \\
\hline & $\left(\mathrm{NH}_{4}\right)_{2} \mathrm{SO}_{4}$ & $1.5 \pm 0.07$ & $0.34 \pm 0$ & $4.4 \pm 0.15$ \\
\hline & malt extract & $5.4 \pm 0.03$ & $2.35 \pm 0.37$ & $2.3 \pm 0.38$ \\
\hline & peptone & 0 & 0 & $9.2 \pm 0.36$ \\
\hline & yeast extract & $1.0 \pm 0.03$ & $0.15 \pm 0.07$ & $6.7 \pm 0.51$ \\
\hline \multirow[t]{5}{*}{ glucose } & $\mathrm{NH}_{4} \mathrm{H}_{2} \mathrm{PO}_{4}$ & $3.3 \pm 0.19$ & $0.29 \pm 0.07$ & $11.5 \pm 0.14$ \\
\hline & $\left(\mathrm{NH}_{4}\right)_{2} \mathrm{SO}_{4}$ & $2.1 \pm 0.12$ & $0.37 \pm 0.01$ & $5.7 \pm 0.60$ \\
\hline & malt extract & $9.3 \pm 0.83$ & $2.39 \pm 0.07$ & $3.9 \pm 0.53$ \\
\hline & peptone & 0 & 0 & $10.3 \pm 0.58$ \\
\hline & yeast extract & $1.8 \pm 0.15$ & $0.16 \pm 0.02$ & $11.0 \pm 1.08$ \\
\hline \multirow[t]{5}{*}{ lactose } & $\mathrm{NH}_{4} \mathrm{H}_{2} \mathrm{PO}_{4}$ & 0 & 0 & $3.0 \pm 0.69$ \\
\hline & $\left(\mathrm{NH}_{4}\right)_{2} \mathrm{SO}_{4}$ & $0.7 \pm 0.09$ & $0.58 \pm 0.05$ & $1.2 \pm 0.63$ \\
\hline & malt extract & $7.1 \pm 0.58$ & $2.54 \pm 0.65$ & $2.8 \pm 0.70$ \\
\hline & peptone & 0 & 0 & $9.4 \pm 0.25$ \\
\hline & yeast extract & 0 & 0 & $11.0 \pm 0.89$ \\
\hline \multirow[t]{5}{*}{ maltose } & $\mathrm{NH}_{4} \mathrm{H}_{2} \mathrm{PO}_{4}$ & $2.5 \pm 0.04$ & $0.40 \pm 0$ & $6.2 \pm 0.13$ \\
\hline & $\left(\mathrm{NH}_{4}\right)_{2} \mathrm{SO}_{4}$ & $1.6 \pm 0.13$ & $0.4 \pm 0.11$ & $4.0 \pm 0.36$ \\
\hline & malt extract & $9.8 \pm 0.28$ & $2.39 \pm 0.39$ & $4.1 \pm 0.42$ \\
\hline & peptone & 0 & 0 & $8.1 \pm 0.93$ \\
\hline & yeast extract & $1.0 \pm 0.06$ & $0.10 \pm 0.01$ & $10.8 \pm 0.87$ \\
\hline \multirow[t]{5}{*}{ mannose } & $\mathrm{NH}_{4} \mathrm{H}_{2} \mathrm{PO}_{4}$ & $2.6 \pm 0.20$ & $0.35 \pm 0.02$ & $7.5 \pm 0.62$ \\
\hline & $\left(\mathrm{NH}_{4}\right)_{2} \mathrm{SO}_{4}$ & $1.3 \pm 0.03$ & $0.24 \pm 0.01$ & $5.4 \pm 0.05$ \\
\hline & malt extract & $7.9 \pm 0.37$ & $2.93 \pm 0.14$ & $2.7 \pm 0.02$ \\
\hline & peptone & $1.9 \pm 0.88$ & $0.22 \pm 0.12$ & $8.5 \pm 0.06$ \\
\hline & yeast extract & $2.0 \pm 0.09$ & $0.17 \pm 0.01$ & $11.9 \pm 0.72$ \\
\hline
\end{tabular}

the lowest in medium 13 (1.14), a multiplication factor of 2.9. The magnitude of differences in responses combined with a low variation at the center demonstrated that the experimental parameters influenced the selected answers in the experimental domain evaluated. For determination of accuracy of the results, variations of the three responses were evaluated with 4 repetitions at the center. For biopolymer production, the mean was 11.69 , standard deviation 0.398 and coefficient of variation $3.4 \%$; for biomass, mean was 3.93, standard deviation 0.11 and coefficient of variation 2.8\%; and for biopolymer yield, mean was 2.96, standard deviation 0.153 and coefficient of variation $5.2 \%$. These results showed that the coefficient of variation was low and the accuracy high. Statisti- cal analysis of the results allowed the determination of their significance and the experimental equation that associated the variables with the results. The complete factorial analysis allowed evaluation of each variable (A, B $C, D, E)$ and also of their interactions $(A B, A C, A D, A E$, $\mathrm{BC}, \mathrm{BD}, \mathrm{BE}, \mathrm{CD}, \mathrm{CE}, \mathrm{DE}$ ). The following equations give the mean, the coefficient of the influence of each factor and the coefficients of the effects of the interactions:

Biopolymer $\left(\mathrm{g} \cdot \mathrm{L}^{-1}\right)=9.93+1.51 \mathrm{~A}+0.75 \mathrm{~B}-0.13 \mathrm{C}+0.064 \mathrm{D}-1.47 \mathrm{E}$ $+0.18 \mathrm{AB}+0.27 \mathrm{AC}+0.12 \mathrm{AD}+0.67 \mathrm{AE}+0.30 \mathrm{BC}+0.057 \mathrm{BD}$ $-0.051 \mathrm{BE}+0.26 \mathrm{CD}-0.21 \mathrm{CE}-0.16 \mathrm{DE}$ 
Table 2: Factors and levels used in two-level fractional factorial design.

\begin{tabular}{cccc}
\hline Factor & Low level (-1) & Center point (0) & High level (+1) \\
\hline A & 20 & 40 & 60 \\
B & 6 & 10 & 14 \\
C & 0 & 1 & 2 \\
D & 0 & 1 & 2 \\
E & 25 & 27.5 & 30 \\
\hline
\end{tabular}

$A=$ glucose $\left(g \cdot L^{-1}\right), B=$ malt extract $\left(g \cdot L^{-1}\right), C=$ vitamin solution $\left(\mathrm{mL} . \mathrm{L}^{-1}\right), \mathrm{D}=$ trace element solution $\left(\mathrm{mL} . \mathrm{L}^{-1}\right), \mathrm{E}=$ temperature $\left({ }^{\circ} \mathrm{C}\right)$

Yield $\left(\mathrm{g} \cdot \mathrm{g}^{-1}\right)=2.19-0.01 \mathrm{~A}+0.05 \mathrm{~B}-0.11 \mathrm{C}-0.08 \mathrm{D}-0.62 \mathrm{E}$

$+0.11 \mathrm{AB}-0.01 \mathrm{AC}-0.04 \mathrm{AD}+0.28 \mathrm{AE}+0.11 \mathrm{BC}-0.05 \mathrm{BD}+0.01 \mathrm{BE}+0.10 \mathrm{CD}$ $-0.04 \mathrm{CE}-0.06 \mathrm{DE}$

$\operatorname{Biomass}\left(\mathrm{g} \cdot \mathrm{L}^{-1}\right)=4.78+0.60 \mathrm{~A}+0.26 \mathrm{~B}+0.12 \mathrm{C}+0.24 \mathrm{D}+0.64 \mathrm{E}$ $-0.26 \mathrm{AB}+0.27 \mathrm{AC}+0.055 \mathrm{AD}-0.13 \mathrm{AE}-0.11 \mathrm{BC}+0.22 \mathrm{BD}+0.044 \mathrm{BE}$ $-0.23 \mathrm{CD}+0.018 \mathrm{CE}+0.092 \mathrm{DE}$

where $\mathrm{A}=$ glucose, $\mathrm{B}=$ malt extract, $\mathrm{C}=$ vitamin solution, $\mathrm{D}=$ trace element solution, and $\mathrm{E}=$ temperature.

The statistical analyses of this experimental design are presented in Table 4, 5 and 6 . The quantity of glucose (A) had the strongest positive influence on biopolymer production, ranging from 20 and $60 \mathrm{~g} \cdot \mathrm{L}^{-1}$, and had a positive effect on biomass but did not influence yield. The quantity of malt extract (B), ranging from 6 to $14 \mathrm{~g} \cdot \mathrm{L}^{-1}$, showed medium positive influence on production and biomass, and thus had no effect on yield. The addition of a vitamin mixture $(C)$ to the production media influenced only slightly the three responses, as well as the addition of a trace element solution (D). Temperature (E) had a strong effect on the three dependant variables in the range 25 to $30^{\circ} \mathrm{C}$. Biopolymer production was maximal at $25^{\circ} \mathrm{C}$, while maximal biomass was obtained at $30^{\circ} \mathrm{C}$ (Figure $1 \mathrm{~A}$ and 1B). However, the increase of temperatures had a negative influence on the yield. This might be due to the reduction at high temperature of viscosity due to exobiopolymer, resulting in a higher rate of glucose uptake for biomass production.

The interactions observed in the experimental domain (from - 1 to +1 ) were limited, except for the positive interaction between the quantity of glucose and temperature on biopolymer yield, and the negative interaction between glucose and malt extract on biomass. Figure 2 shows the response surface and contour plot with glucose concentration and temperature as experimental factors and biopolymer production as response. This figure was obtained with all results including center point. Based on this information the best combination was glucose 60 g.L-1, malt extract $14 \mathrm{~g} \cdot \mathrm{L}-1$, and temperature $25^{\circ} \mathrm{C}$, which is similar to combinations 8 and 12 of the experimental designs. Those 2 combinations gave the higher amount of biopolymer and good yield.

Besides detecting the most important variables of the system, the optima could be located as being inside the experimental region evaluated (between the values -1 and +1 ) or outside (more than +1 or less than -1 ). This was analyzed by comparing the general mean of the factorial experiments and the value at the center point (curvature), There was a difference between the average value of the 16 combinations calculated from the two-level fractional factorial design $\left(4.8 \mathrm{~g} \cdot \mathrm{L}^{-1}, 9.9 \mathrm{~g} \cdot \mathrm{L}^{-1}\right.$ and $2.2 \mathrm{~g} \cdot \mathrm{g}^{-1}$, for biomass, exobiopolymer and yield, respectively) and the average results at the center point $\left(4.0 \mathrm{~g} \cdot \mathrm{L}^{-1}, 11.7 \mathrm{~g} \cdot \mathrm{L}^{-1}\right.$ and $3.0 \mathrm{~g} \cdot \mathrm{g}^{-1}$, for biomass, exobiopolymer and yield, respectively). The values at the center points were higher for the 3 responses. There is a significant curvature, although of limited extent. So it is likely that the optima are located in the experimental space evaluated near the best levels, -1 or +1 depending on each factor and its influence. For the next step, the center was chosen as control in addition to the combination giving the highest production.

\section{Exobiopolymer production in bioreactor}

At the center point $\left(40 \mathrm{~g} \cdot \mathrm{L}^{-1}\right.$ glucose, $10 \mathrm{~g} \cdot \mathrm{L}^{-1}$ malt extract, $1 \mathrm{~mL} \cdot \mathrm{L}^{-1}$ vitamin solution, $1 \mathrm{~mL} \cdot \mathrm{L}^{-1}$ trace solution, and $27.5^{\circ} \mathrm{C}$ ), a specific growth rate $(\mu)$ of $O$. dipterigena $\mathrm{BCC}$ 2073 of $0.012 \mathrm{~h}^{-1}$ was obtained, with biomass yield $\left(Y_{X S}\right)$ of $0.18 \mathrm{~g} \cdot \mathrm{g}^{-1}$ glucose, exobiopolymer yield $\left(Y_{X P}\right)$ of $2.78 \mathrm{~g} \cdot \mathrm{g}-$ $1_{\text {biomass }}$, yield on substrate $\left(Y_{S P}\right)$ of $0.48 \mathrm{~g} \cdot \mathrm{g}^{-1}$ sugar, and exobiopolymer production rate $\left(q_{p}\right)$ of $0.66 \mathrm{~g} \cdot(\mathrm{L} \cdot \mathrm{d})^{-1}$ (Figure $3 \mathrm{~A})$. The maximal exobiopolymer amount $\left(23.8 \mathrm{~g} \cdot \mathrm{L}^{-1}\right)$ was obtained at $232 \mathrm{~h}$. At the best level of the factorial design (60 g. $\mathrm{L}^{-1}$ glucose, $14 \mathrm{~g} \cdot \mathrm{L}^{-1}$ malt extract, $1 \mathrm{~mL} \cdot \mathrm{L}^{-1}$ vitamin solution, $1 \mathrm{~mL} \cdot \mathrm{L}^{-1}$ trace solution, and $25^{\circ} \mathrm{C}$ ), $\mu$ of $0.014 \mathrm{~h}^{-1}$ was obtained, with $Y_{S X}$ of $0.32 \mathrm{~g}^{\mathrm{g}} \mathrm{g}^{-1}$ glucose, $Y_{X P}$

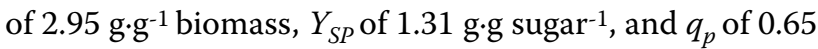
g.(L.d $)^{-1}$ (Figure 3B). A Maximal exobiopolymer concentration $\left(41.2 \mathrm{~g} \cdot \mathrm{L}^{-1}\right)$ was reached at $377 \mathrm{~h}$. Production was higher than the one observed at the center point by a factor of 1.7. As regards production rate, the best level condition gave a little higher value than the center point condition (2.64 g.(L.day) $)^{-1}$ and $2.40 \mathrm{~g}$.(L.day) $)^{-1}$ for the best level and the center point respectively). The slower rate of glucose uptake after $377 \mathrm{~h}$ might be due to an increase in viscosity due to the high exobiopolymer concentration. Residual glucose was high, $4 \mathrm{~g} \cdot \mathrm{L}^{-1}$ under "center point" conditions and $18 \mathrm{~g} \cdot \mathrm{L}^{-1}$ in the medium with high glucose and malt extract concentrations. Thus, the optimal condition obtained from the two-level fractional factorial design resulted in a significant increase of exobiopolymer production in a bioreactor compared with reference conditions and with the screening conditions used initially. 
Table 3: Biomass and exobiopolymer production using a two-level fractional factorial design with 5 factors $\left(2^{\mathrm{n}-1}\right)$.

\begin{tabular}{|c|c|c|c|c|c|c|c|c|}
\hline No. & $\begin{array}{l}\text { Glucose } \\
\left(g \cdot L^{-1}\right)\end{array}$ & $\begin{array}{l}\text { Malt } \\
\text { extract }\left(g \cdot L^{-1}\right)\end{array}$ & $\begin{array}{l}\text { Vitamin } \\
\text { solution } \\
\text { (mL.L-1) }\end{array}$ & $\begin{array}{l}\text { Trace element } \\
\text { solution }\left(\mathrm{mL} \cdot \mathrm{L}^{-1}\right)\end{array}$ & $\begin{array}{c}\text { Temp. } \\
\left({ }^{\circ} \mathrm{C}\right)\end{array}$ & $\begin{array}{l}\text { Exobiopolymer } \\
\left(\mathbf{g} \cdot \mathrm{L}^{-1}\right)\end{array}$ & Yield $\left(\mathbf{g} \cdot \mathrm{g}^{-1}{ }_{\text {biomsdd }}\right)$ & $\begin{array}{l}\text { Biomass } \\
\left(g \cdot L^{-1}\right)\end{array}$ \\
\hline 1 & 20 & 6 & 0 & 0 & 30 & $7.2 \pm 0.27$ & $1.76 \pm 0.03$ & $4.1 \pm 0.24$ \\
\hline 2 & 60 & 6 & 0 & 0 & 25 & $11.2 \pm 0.21$ & $2.67 \pm 25$ & $4.2 \pm 0.63$ \\
\hline 3 & 20 & 14 & 0 & 0 & 25 & $11.2 \pm 0.92$ & $3.11 \pm 0$ & $3.6 \pm 0.77$ \\
\hline 4 & 60 & 14 & 0 & 0 & 30 & $11.5 \pm 0.25$ & $2.40 \pm 0.13$ & $4.8 \pm 0.42$ \\
\hline 5 & 20 & 6 & 2 & 0 & 25 & $9.1 \pm 0.38$ & $2.84 \pm 0.08$ & $3.2 \pm 0.29$ \\
\hline 6 & 60 & 6 & 2 & 0 & 30 & $9.2 \pm 0.23$ & $1.44 \pm 0.01$ & $6.4 \pm 0.21$ \\
\hline 7 & 20 & 14 & 2 & 0 & 30 & $6.4 \pm 0.07$ & $1.28 \pm 0.04$ & $5.0 \pm 0.53$ \\
\hline 8 & 60 & 14 & 2 & 0 & 25 & $13.2 \pm 0.74$ & $2.70 \pm 0.02$ & $4.9 \pm 0.15$ \\
\hline 9 & 20 & 6 & 0 & 2 & 25 & $10.2 \pm 0.08$ & $3.29 \pm 0.14$ & $3.1 \pm 0.21$ \\
\hline 10 & 60 & 6 & 0 & 2 & 30 & $9.8 \pm 0.60$ & $1.72 \pm 0.03$ & $5.7 \pm 0.07$ \\
\hline 11 & 20 & 14 & 0 & 2 & 30 & $6.7 \pm 0.16$ & $1.03 \pm 0.04$ & $6.5 \pm 0.36$ \\
\hline 12 & 60 & 14 & 0 & 2 & 25 & $12.7 \pm 0.09$ & $2.44 \pm 0.06$ & $5.2 \pm 0.50$ \\
\hline 13 & 20 & 6 & 2 & 2 & 30 & $4.8 \pm 0.08$ & $1.14 \pm 0.23$ & $4.2 \pm 0.75$ \\
\hline 14 & 60 & 6 & 2 & 2 & 25 & $11.8 \pm 0.62$ & $2.27 \pm 0.01$ & $5.2 \pm 0.90$ \\
\hline 15 & 20 & 14 & 2 & 2 & 25 & $11.7 \pm 0.14$ & $3.16 \pm 0.04$ & $3.7 \pm 0.47$ \\
\hline 16 & 60 & 14 & 2 & 2 & 30 & $12.1 \pm 0.35$ & $1.83 \pm 0.06$ & $6.6 \pm 0.49$ \\
\hline 17 & 40 & 10 & 1 & 1 & 27.5 & $12.1 \pm 0.50$ & $3.03 \pm 20$ & $4.0 \pm 1.02$ \\
\hline 18 & 40 & 10 & 1 & 1 & 27.5 & $11.3 \pm 0.48$ & $2.90 \pm 0.18$ & $3.9 \pm 0.68$ \\
\hline 19 & 40 & 10 & 1 & 1 & 27.5 & $11.4 \pm 0.13$ & $2.78 \pm 0.04$ & $4.1 \pm 0.30$ \\
\hline 20 & 40 & 10 & 1 & 1 & 27.5 & $11.9 \pm 0.20$ & $3.13 \pm 0.14$ & $3.8 \pm 1.21$ \\
\hline
\end{tabular}

In all the fermentations, the mycelium remained disperse without formation of cotton flogs or pellets. This type of growth combined with the viscosity of the exobiopolymer reduces mass and heat transfer.

\section{Characterization of exobiopolymer}

Exobiopolymer produced by O. dipterigena BCC 2073 harvested at different cultivation times showed identical sizes (Figure 4), in the range $6.3 \times 10^{5}-7.7 \times 10^{5} \mathrm{Da}$ (see Additional file 1 ). The maximal IL- 8 synthesis induced by 
$50 \mu \mathrm{g} \cdot \mathrm{mL}^{-1}$ and $100 \mu \mathrm{g} \cdot \mathrm{mL}^{-1}$ exobiopolymer $\left(7.0 \times 10^{5} \mathrm{Da}\right.$ obtained at $335 \mathrm{~h}$ growth) was 2227 and $3363 \mathrm{pg} \cdot \mathrm{mL}^{-1}$ respectively.

\section{Discussion}

The sequential strategy used in this project, namely a full experimental design for the selection of the best carbon and nitrogen sources, a factorial design at 2 levels for the determination of the optimal levels of 5 quantitative factors and up-scaling for confirmation and development, was promising both in terms of quantity and quality. Production of exobiopolymer by O. dipterigena BCC 2073 obtained from this optimization $\left(41.2 \mathrm{~g} \cdot \mathrm{L}^{-1}\right.$ in a 5 -liter bioreactor) showed suitability for industrial development. This is the first report of such a high production of a characterized biopolymer. The biopolymer was biologically active when tested for induction of IL- 8 by normal dermal fibroblasts.

Production of exobiopolymers by strains of other genera but belonging to the same group is significantly lower. The amounts of exobiopolymer by Paecilomyces japonica in a 5-liter bioreactor varies from 8 to $34.5 \mathrm{~g} \cdot \mathrm{L}^{-1}$ depending on the type and quantity of the carbon source $[26,27,32]$. Other strains are relatively poor producers under the tested cultivation conditions: about $2 \mathrm{~g} \cdot \mathrm{L}^{-1}$ exobiopolymer by P. sinclairii [9], 3.4 g.L.-1 by Paecilomyces tenuipes [32], and 10.3 g.L.-1 by Cordyceps militaris is [13] and more than $15 \mathrm{~g} \cdot \mathrm{L}^{-1}$ after physical optimization $[14,15]$. Our process has two main advantages, namely, high level of production and characterization of the product. Biopolymer from prokaryotes contain a wide variety of sugars, thus they are different in sizes and molecular weights, resulting in IL-8 induction at varying levels [7].

Glucose was the favored of the tested carbon types followed by mannose and maltose. Maltose is an often used carbon source for the production of exobiopolymer. Malt extract was the best nitrogen source for exobiopolymer synthesis by $O$. dipterigena BCC 2073, and this might be due to the fact that maltose with glucose are two main precursors of the biopolymer. Temperature had an inverse effect on biopolymer concentration and on bio- mass concentration. The production of exobiopolymer by O. dipterigena $\mathrm{BCC} 2073$ under the optimized conditions was reproducible in the 5-liter bioreactor (data not shown). This process in liquid culture will facilitate downstream processes, which will help lower the cost of production.

High exobiopolymer amounts cause high viscosity of the fermentation medium, resulting in slower sugar uptake rate in the latter days of cultivation, difficulty in mixing, and low rate of oxygen transfer. Those problems were increased by the morphology of the mycelia, which remained disperse. Thus fungus grew slower, affecting sugar uptake rate and resulting in a high sugar residue on the last day of cultivation. This high level of unconsumed sugar can be a problem in downstream process. This problem could be solved by feeding glucose. Furthermore, this was difficult to obtain growth-associated production of exobiopolymer and biomass (Figure 3). The type of mycelium morphology and disperse growth constitute further problems of power consumption and maintenance of DO concentration. This is clearly seen that effects of aeration and agitation using bioreactor on higher exobiopolymer production by $O$. dipterigena BCC 2073 was obtained compared with shake flasks. A pellet formation by Paecilomyces japonica at low agitation rate, high aeration and optimum substrate concentration results in the best production of exobiopolymer $[27,28]$. The fungal morphology of our strain will need to be controlled in order to increase substrate uptake rate and oxygen transfer rate. This could be achieved by controlling the fungal morphology as pellet with small areas. Production of fungal metabolites has been increased by control of their morphology [34,35], thus improving the rheology of fermentation medium [36,37]. Agitation conditions, inoculum levels, $\mathrm{pH}$ and dissolved oxygen tension will be parameters to be investigated further.

\section{Conclusions}

High exobiopolymer yield produced by $O$. dipterigena BCC 2073, after optimization by qualitative and quantitative techniques, is attractive for various applications. The

Table 4: Analysis of variance (ANOVA) for two-level fractional factorial design $\left(2^{n-1}\right)$ of exobiopolymer production by 0. dipterigena BCC 2073.

\begin{tabular}{lccccc}
\hline Source & Sum of squares & D.F. & Mean square & F-value & Probability $(\boldsymbol{P})>\boldsymbol{F}$ \\
\hline Model* & 93.02 & 15 & 6.20 & 39.09 & 0.0058 \\
Curvature* $^{*}$ & 9.89 & 1 & 9.89 & 62.36 & 0.0042 \\
Pure error & 0.48 & 3 & 0.16 & \\
Corrected total & 103.39 & 19 & & \\
$\mathrm{R}^{2}=0.9949$, adj-R ${ }^{2}=0.9695, \mathrm{SD}=0.40$, Mean $=10.28, \% \mathrm{CV}=3.88$ & & \\
\hline
\end{tabular}

*significant 
exobiopolymer induced high IL-8 production by normal dermal fibroblasts, which makes it promising for application as wound healing material. However, there are still other possible applications of this biopolymer, such as an alternative source of biopolymer for hyaluronic acid, which is costly, as a thickening agent in the cosmetic industry due to its high viscosity property, as a moisturizer, and in encapsulation.

\section{Methods}

Fungal strain and cultivation

Entomopathogenic fungus Ophiocordyceps dipterigena BCC 2073 was kindly provided by Dr. Nigel L. HywelJones, National Center for Genetic Engineering and Biotechnology (BIOTEC), National Science and Technology Development Agency, Thailand and has been deposited in BIOTEC Culture Collection, which is publicly accessible.

\section{Inoculum}

O. dipterigena $\mathrm{BCC} 2073$ was grown initially on potato dextrose agar (PDA) at $25^{\circ} \mathrm{C}$ for 5-7 days. An agar block (1 $\mathrm{cm}^{3}$ )containing the growing culture was cut into small pieces and transferred to $25 \mathrm{ml}$ of potato dextrose broth (PDB) in a $250 \mathrm{~mL}$ Erlenmeyer flask. This liquid seed culture was incubated for $5-7$ days at $25^{\circ} \mathrm{C}$ on a rotary shaker (200 rpm) (New Brunswick, NJ, USA).

\section{Fermentation conditions}

Seed culture, $10 \%(\mathrm{v} / \mathrm{v})$, was transferred into $50 \mathrm{ml}$ of liquid production medium (20 g. $\mathrm{L}^{-1}$ sugar, $10 \mathrm{~g} \cdot \mathrm{L}^{-1}$ nitrogen source 0.5 g.L $\mathrm{L}^{-1} \mathrm{KH}_{2} \mathrm{PO}_{4}, 0.2 \mathrm{~g} \cdot \mathrm{L}^{-1} \mathrm{~K}_{2} \mathrm{HPO}_{4}, 0.2 \mathrm{~g} \cdot \mathrm{L}^{-1}$ $\mathrm{MgSO}_{4} \cdot 7 \mathrm{H}_{2} \mathrm{O}$, and $0.14 \mathrm{~g} \cdot \mathrm{L}^{-1} \mathrm{MnSO}_{4} \cdot \mathrm{H}_{2} \mathrm{O}$ ) in $250 \mathrm{~mL}$ Erlenmeyer-flask. The carbon sources tested were galactose, glucose, lactose, maltose, and mannose. The nitrogen sources evaluated were $\mathrm{NH}_{4} \mathrm{H}_{2} \mathrm{PO}_{4},\left(\mathrm{NH}_{4}\right)_{2} \mathrm{SO}_{4}$, malt extract, peptone, and yeast extract. All 25 combinations were tested in the full experimental design. Those cultures were incubated for 7 days at $25^{\circ} \mathrm{C}$ on a rotary shaker (200 rpm).

The medium used in a 5-liter fermenter (Marubishi Co., Ltd., Nonthaburi, Thailand) with a working volume of $4 \mathrm{~L}$ had the following composition: $60 \mathrm{~g} \cdot \mathrm{L}^{-1}$ glucose, 14 g. $\mathrm{L}^{-1}$ malt extract, 0.5 g. $\mathrm{L}^{-1} \mathrm{KH}_{2} \mathrm{PO}_{4}, 0.2$ g.L $\mathrm{L}^{-1} \mathrm{~K}_{2} \mathrm{HPO}_{4}, 0.2$ g. $\mathrm{L}^{-1} \mathrm{MgSO}_{4} \cdot 7 \mathrm{H}_{2} \mathrm{O}, 0.14 \mathrm{~g} \cdot \mathrm{L}^{-1} \mathrm{MnSO}_{4} \cdot \mathrm{H}_{2} \mathrm{O}$, and $1 \mathrm{~mL} \cdot \mathrm{L}^{-1}$ vitamin solution (Blackmores, NSW, Australia). Vitamin complex consisted of $75 \mathrm{mg}$ vitamin B1 (thiamine hydrochloride), $10 \mathrm{mg}$ vitamin B2 (riboflavin), $50 \mathrm{mg}$ nicotinamide, $25 \mathrm{mg}$ calcium pantothenate, $10 \mathrm{mg}$ vitamin B6 (pyridoxine hydrochloride), $25 \mathrm{mcg}$ vitamin B12 (cyanocobalamin), $15 \mathrm{mcg}$ biotin, $500 \mathrm{mg}$ vitamin $\mathrm{C}$ (derived from ascorbic acid $260 \mathrm{mg}$ and calcium ascorbate 290.5 $\mathrm{mg}), 10 \mathrm{mg}$ choline bitartrate, $10 \mathrm{mg}$ inositol, $10 \mathrm{mg}$ zinc amino acid chelate (zinc $2 \mathrm{mg}$ ), $175 \mathrm{mg}$ calcium phosphate, and $75 \mathrm{mg}$ magnesium phosphate. Trace element solution contained (per L) $14.3 \mathrm{~g}$ of $\mathrm{ZnSO}_{4} \cdot \mathrm{H}_{2} \mathrm{O}, 2.5 \mathrm{~g}$ of $\mathrm{CuSO}_{4} \cdot 5 \mathrm{H}_{2} \mathrm{O}, 0.5 \mathrm{~g}$ of $\mathrm{NiCl}_{2} \cdot 6 \mathrm{H}_{2} \mathrm{O}$ and $13.8 \mathrm{~g}$ of $\mathrm{FeSO}_{4} \cdot \mathrm{H}_{2} \mathrm{O}$. Culture was agitated at $300 \mathrm{rpm}$ and aerated at 1 vvm. pH was not automatically adjusted.

\section{Biomass determination}

Whole cultures were used in the case of flask fermentation and $40 \mathrm{ml}$ aliquots of the homogeneous culture in bioreactor. Broth was centrifuged at $10,000 \mathrm{~g}$ for $10 \mathrm{~min}$ and supernatant was removed. The mycelium was re-suspended in 20-30 mL of normal saline and filtered through Whatman No 1 filter paper. The filter cake was washed with distilled water and dried at $105-110^{\circ} \mathrm{C}$ for $24-48 \mathrm{~h}$ until a stable weight was achieved. Culture filtrate was subjected to sugar analysis and exobiopolymer extraction.

\section{Exobiopolymer purification and quantification}

Culture filtrate was mixed with four volumes of $95 \%$ ethanol, stirred vigorously for $10-15 \mathrm{~min}$. and stored at $20^{\circ} \mathrm{C}$ for at least $12 \mathrm{~h}$. Precipitated polymer was sedimented at $10,000 \mathrm{~g}$ for $20 \mathrm{~min}$ and lyophilized. Polymer was dissolved in distilled water and any insoluble material was removed by centrifugation at 10,000 $g$ for $20 \mathrm{~min}$. Supernatant was dialyzed ( $2 \mathrm{kDa}$ cut off; Spectrum Laboratories, Inc., USA) against $4 \mathrm{~L}$ of distilled water for $24 \mathrm{~h}$ and lyophilized. The aim of the dialysis is to eliminate salts and sugars, which would interfere with biopolymer characterization. The dried biopolymer was then weighed until stable weight was achieved.

\section{Exobiopolymer molecular weight determination}

The average molecular weight of the polymers was determined by gel-permeation chromatography (GPC) (Waters 600E; Waters, MA, USA); the machine is equipped with a refractive index (RI) detector and an Ultrahydrogel linear column $(300 \times 7.8 \mathrm{~mm}$ ID; Waters, USA). Universal calibration log (Mp) versus VR, where $\mathrm{Mp}$ is the peak molecular weight, was conducted with dextran standards of molecular weights ranging from 4,400 to 401,000 . Injection volume was $20 \mu \mathrm{l}$ and flow rate of the mobile phase $(0.05 \mathrm{M}$ sodium bicarbonate buffer) was $0.6 \mathrm{ml} / \mathrm{min}$.

\section{Sugar determination}

Supernatant was centrifuged at $10,000 \mathrm{~g}$ for $10 \mathrm{~min}$ and filtered through $0.22 \mu \mathrm{m}$ filter paper. Filtrate was subjected to HPLC analysis using a Sugar-Pak column (Waters, MA, USA) at $90^{\circ} \mathrm{C}$, with water as mobile phase at a flow rate of $0.6 \mathrm{~mL} . \mathrm{min}^{-1}$ and a pressure of 900-1000 psi. Sugars were detected by refractometry (Waters 410 Differential Refractometer Detector, Millipore Corp., Milford, MA, USA). 
Table 5: Analysis of variance (ANOVA) for two-level fractional factorial design $\left(2^{n-1}\right)$ of exobiopolymer yield by 0. dipterigena BCC 2073.

\begin{tabular}{lccccc}
\hline Source & Sum of squares & D.F. & Mean square & F-value & Probability $(\boldsymbol{P})>\boldsymbol{F}$ \\
\hline Model* $^{*}$ & 8.40 & 15 & 0.56 & 24.06 & 0.0117 \\
Curvature* $^{*}$ & 1.88 & 1 & 1.88 & 81.02 & 0.0029 \\
Pure error & 0.07 & 3 & 0.02 & \\
Corrected total & 10.35 & 19 & & \\
$\mathrm{R}^{2}=0.9918$, adj-R ${ }^{2}=0.9505, \mathrm{SD}=0.15$, Mean $=2.35, \% \mathrm{CV}=6.50$ & & \\
\hline${ }^{*}$ significant
\end{tabular}

${ }^{*}$ significant

\section{Interleukin-8 (IL-8) production determination}

Normal dermal human fibroblasts were cultured in a 96well microtiter plate at a concentration of $3 \times 10^{3}$ cells/ $100 \mu \mathrm{l} /$ well in Dubelco's modified Eagle medium (DMEM) supplemented with heat inactivated $10 \%$ fetal bovine serum and incubated at $37^{\circ} \mathrm{C}$ in a humidified incubator under an atmosphere containing $5 \% \mathrm{CO}_{2}$. Fresh medium containing various concentrations of polymers was added after $48 \mathrm{~h}$, and the cell suspensions were incubated for an additional $48 \mathrm{~h}$. Supernatants were collected and IL-8 levels were determined using h-IL-8 ELISA kit (Roche Applied Science, Germany).

\section{Experimental designs}

A full factorial design was used to determine the optimal carbon and nitrogen sources. Twenty g. $\mathrm{L}^{-1}$ carbon (galactose, glucose, lactose, maltose, mannose) and $10 \mathrm{~g} \cdot \mathrm{L}^{-1}$ nitrogen sources $\left(\mathrm{NH}_{4} \mathrm{H}_{2} \mathrm{PO}_{4},\left(\mathrm{NH}_{4}\right)_{2} \mathrm{SO}_{4}\right.$, malt extract, peptone, yeast extract) were combined in a basic medium. All 25 combinations (Table 1) were tested, which allows a clear selection of the best carbon and nitrogen sources. The experiments were conducted in duplicate. A model of first order was developed for each answer. The model gives the average of all answers and the contribution of each carbon- and nitrogen-source. Statistical significance was determined by comparison of the coefficient of the model with the standard deviation evaluated in the test for accuracy.
Following this selection, the influence of 5 physiological quantitative factors (glucose concentration, malt extract concentration, trace element solution, vitamin solution, temperature) on exobiopolymer production was evaluated using a fractional factorial design at 2 levels. The five quantitative factors were tested each at two levels: a minimal quantity (coded -1) and a maximal quantity (coded +1 ). The real and the coded values of each experimental factor can be found in Table 2. The coding of the factors allows an easy and clear estimation of the effects of the factors (how changing the setting of a factor changes the response) and interactions (when the effect of one factor on a response depends on the level of another factor). The full factorial design at 2 levels with 5 factors requires the evaluation of 32 combinations. Thus a reduced design, called fractional factorial, with only 16 combinations was used. Such a design remains balanced (all factors have the same number of observations) and orthogonal (the main effects and the interactions between 2 factors can be estimated with any confusion). This design allows the determination of the following linear regression model:

$$
\mathrm{Y}=\mathrm{b}_{\mathrm{o}}+\mathrm{b}_{\mathrm{i}} \mathrm{X}_{\mathrm{i}}+\mathrm{b}_{\mathrm{ij}} \mathrm{X}_{\mathrm{i}} \cdot \mathrm{X}_{\mathrm{j}}
$$

where: - $\mathrm{Y}$ is the response (yield of biopolymer)

- $b_{o}$ represents the overall mean

Table 6: Analysis of variance (ANOVA) for two-level fractional factorial design $\left(2^{\mathrm{n}-1}\right)$ of biomass production by 0 . dipterigena BCC 2073.

\begin{tabular}{lccccc}
\hline Source & Sum of squares & D.F. & Mean square & F-value & Probability $(\boldsymbol{P})>\boldsymbol{F}$ \\
\hline Model $^{*}$ & 19.15 & 15 & 1.28 & 103.55 & 0.0014 \\
Curvature* $^{*}$ & 2.30 & 1 & 2.30 & 186.29 & 0.0009 \\
Pure error & 0.037 & 3 & 0.012 & \\
Corrected total & 21.48 & 19 & & \\
$\mathrm{R}^{2}=0.9981$, adj- $\mathrm{R}^{2}=0.9884, \mathrm{SD}=0.11$, Mean $=4.61, \% \mathrm{CV}=2.41$ & & \\
\hline
\end{tabular}

*significant 


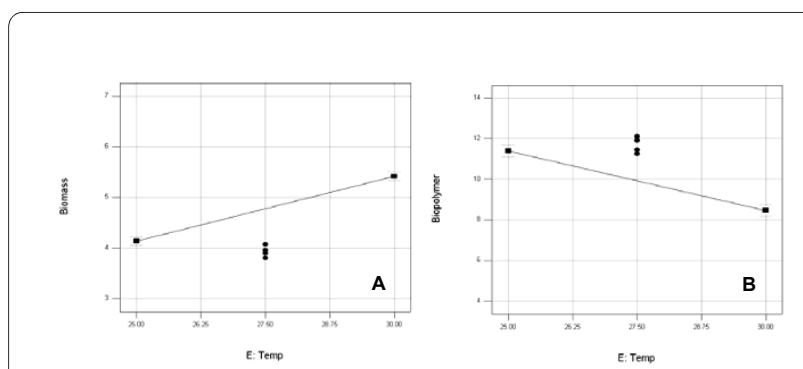

Figure 1 Effects of temperature on biomass and exobiopolymer production of $O$. dipterigena BCC 2073 using a two-level fractional factorial design

- $b_{i}$ the coefficient for each experimental variable

- $b_{i j}$ the coefficient for each interaction between 2 factors.

The center point is the response corresponding to the treatment exactly midway between the two levels of all factors. Performing multiple replicates at this point provides an estimate of pure error, which is evaluated as coefficient of variation (statistical representation of the precision of an assay), standard deviation/mean $\times 100$.

The other advantage of conducting center point replicates in a factorial design at 2 levels is the possibility to evaluate the presence of a curvature. The test for curvature investigates whether the model between the response and the factors is linear and thus if the optima are likewise outside or inside the experimental domain chosen. The average response at the center point (observed value) is compared with the mean of the values obtained with the combinations of the factorial design (in this case 16). If the distance between those 2 values is high, there is a curvature and a model of first order is

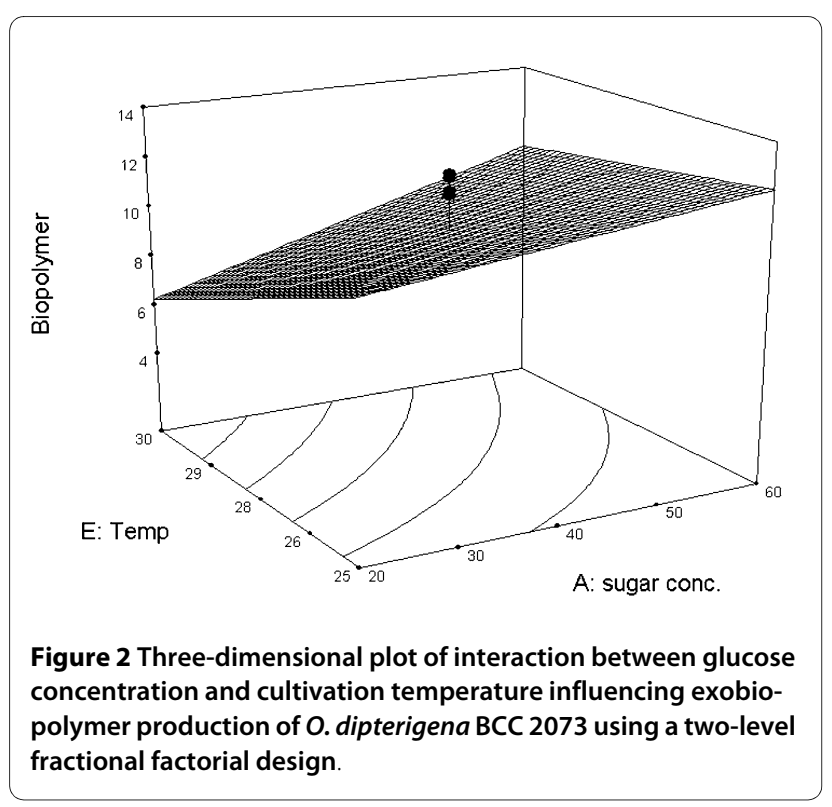

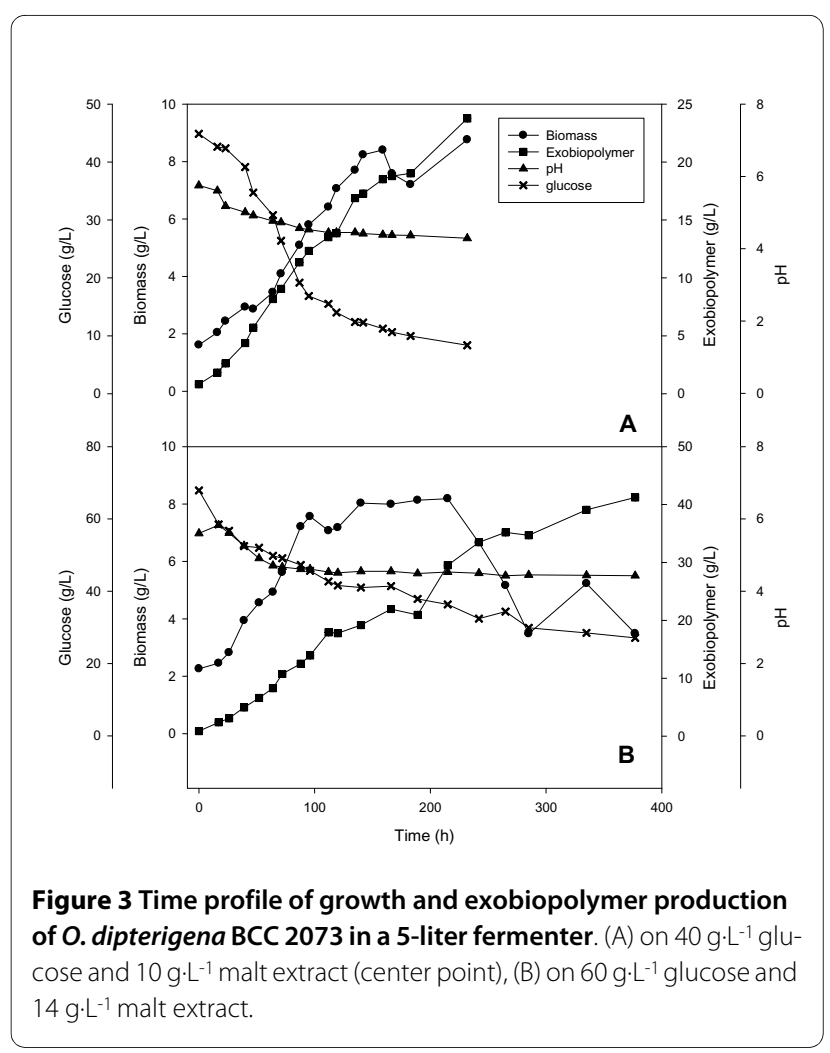

invalid. The center point (coded 0 , not for the absence of compound but for the average quantity between the low and high levels) was repeated 4 times. The other combinations were conducted in duplicate. In these experiments, the production of biopolymer was the main output of the process. In addition, biomass and biopolymer were taken into consideration as secondary responses in order to evaluate the relationship between growth and production. The Design Expert software (Version 7.0.b1.1, Stat-Ease Inc., Minneapolis, USA) was used for experimental design selection, data analysis, sta-

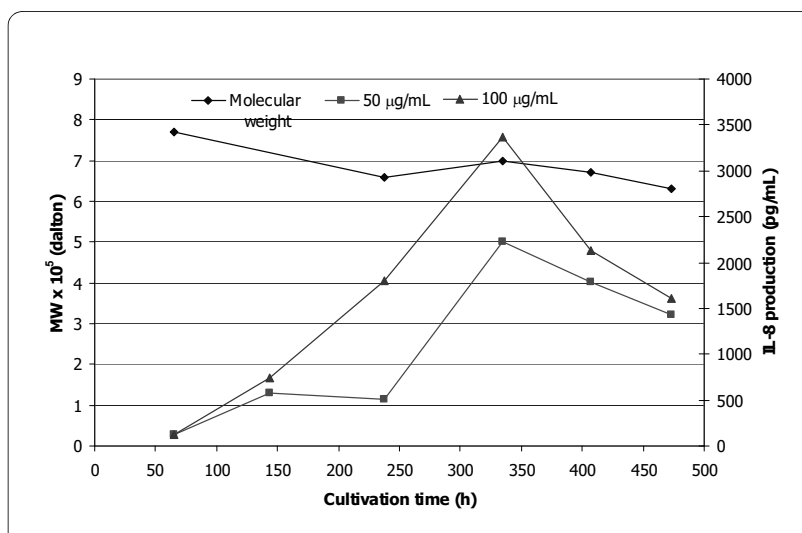

Figure 4 Molecular weight and IL-8 production of $O$. dipterigena BCC 2073 produced in a 5 -liter fermenter at different cultivation times. 
tistical evaluation and model building. Models with terms of interactions were evaluated. The statistical values of the coefficients were evaluated using ANOVA. The value of the model was controlled by the value of $R^{2}$, a statistical measure of how well the model approximates the real data points. An $R^{2}$ value of 1.0 indicates that the model perfectly fits the data. If the value of $R^{2}$ is higher than 0.9 , the value of the model is excellent.

\section{Additional material}

Additional file $1 \mathrm{Gel}$ Permeation Chromatography (GPC) profile of exobiopolymer molecular weight determination. Chromatograms of standard dextrans (MW 4,400-401,000 da) and exobiopolymer at different time profiles.

\section{Authors' contributions}

KK performed the whole experiment with the help of PR. JJS consulted statistical analyses and content of this manuscript. WP designed the experiment and wrote all the manuscript together with KK. JJS reviewed and edited the paper. All authors read and approved the final manuscript.

\section{Acknowledgements}

This project was supported by Bioresource Network Program, National Center for Genetic Engineering and Biotechnology, National Science and Technology Development Agency, Thailand. We thank Prof. Dr. Prapon Wilairat for English proofreading of this manuscript.

\section{Author Details}

${ }^{1}$ National Center for Genetic Engineering and Biotechnology, National Science and Technology Development Agency, 113 Thailand Science Park, Klong 1, Klong Luang, Pathumthani 12120, Thailand and 2 Novartis Institute for BioMedical Research Basel, Natural Products Unit, Novartis Pharma AG, Basel, Switzerland

Received: 26 November 2009 Accepted: 12 July 2010

Published: 12 July 2010

\section{References}

1. Sutherland IW: Bacterial exopolysaccharides-their nature and production. In Surface Carbohydrates of Prokaryotic Cell Edited by: Sutherland IW. London: Academic Press; 1977:27-96.

2. Margaritis A, Pace GW: Microbial Polysaccharides. Adv Biotechnol 1985 2:1005-1042.

3. Chen W, Zhao Z, Chen SF, Li YQ: Optimization for the production of exopolysaccharide from Fomes fomentarius in submerged culture and its antitumor effect in vitro. Biores Techno/ 2008, 99:3187-94.

4. Kim SW, Hwang HJ, Park JP, Cho YJ, Song CH, Yun JW: Mycelial growth and exo-biopolymer production by submerged culture of various edible mushrooms under different media. Lett App/ Microbiol 2002, 34:56-61.

5. Kim HM, Park MK, Yun JW: Culture $\mathrm{pH}$ affects exopolysaccharide production in submerged mycelial culture of Ganoderma lucidum. Appl Biochem Biotechnol 2006, 134:249-62.

6. Tang YJ, Zhong JJ: Exopolysaccharide biosynthesis and related enzyme activities of the medicinal fungus, Ganoderma lucidum, grown on lactose in a bioreactor. Biotechnol lett 2002, 24:1023-1026.

7. Madla S, Methacanon P, Prasitsil M, Kirtikara K: Characterization of biocompatible fungi-derived polymers that induce IL-8 production. Carbohydr Polym 2005, 59:275-280

8. Methacanon P, Madla S, Kirtikara K, Prasitsil M: Structural elucidation of bioactive fungi-derived polymers. Carbohydr Polym 2005, 60:199-203.

9. Kim SW, Hwang HJ, Xu CP, Na YS, Song SK, Yun JW: Influence of nutritional conditions on the mycelial growth and exopolysaccharide production in Paecilomyces sinclairii. Lett App/ Micorbio/ 2002, 34:389-393.
10. Kim SW, Hwang HJ, Xu CP, Sung JM, Choi JW, Yun JW: Optimization of submerged culture process for the production of mycelial biomass and exo-polysaccharides by Cordyceps militaris C738. J App/ Microbiol 2003, 94:120-126.

11. Kim SW, Xu CP, Hwang HJ, Choi JW, Kim CW, Yun JW: Production and characterization of exopolysaccharides from an enthomopathogenic fungus Cordyceps militaris NG3. Biotechnol Prog 2003, 19:428-35.

12. Kim SW, Hwang HJ, Xu CP, Choi JW, Yun JW: Effect of aeration and agitation on the production of mycelial biomass and exopolysaccharides in an enthomopathogenic fungus Paecilomyces sinclairii. Lett Appl Microbiol 2003, 36:321-326.

13. Park JP, Kim SW, Hwang HJ, Yun JW: Optimization of submerged culture condition for the mycelial growth and exo-biopolymer production by Cordyceps militaris. Lett Appl Microbiol 2001, 33:76-81.

14. Park PJ, Kim YM, Kim SW, Hwang HJ, Cho YJ, Lee YS, Song CH, Yun JW: Effect of aeration rate on the mycelial morphology and exobiopolymer production in Cordyceps militaris. Proc Biochem 2002, 37:1257-1262

15. Park PJ, Kim YM, Kim SW, Hwang HJ, Cho YJ, Lee YS, Song CH, Yun JW: Effect of agitation intensity on the exobiopolymer production and mycelial morphology in Cordyceps militaris. Lett Appl Microbiol 2002, 34:433-438

16. Xu CP, Kim SW, Hwang HJ, Choi JW, Yun JW: Optimization of submerged culture conditions for mycelial growth and exo-biopolymer production by Paecilomyces tenuipes C240. Proc Biochem 2003 38:1025-1030

17. Carbonero E, Sassaki G, Stuelp P, Gorin P, Woranovicz-Barreira S, lacomini $\mathrm{M}$ : Comparative studies of the polysaccharides isolated from lichenized fungi of the genus Cladonia: significance as chemotypes. FEMS Microbiol Lett 2001, 194:65-69.

18. Kremer P, Novotny C, Marais MF, Joseleau JP: Structure of extracellular polysaccharide produced by lignin-degrading fungus Phlebia radiata in liquid culture. Biol Macromol 1999, 24:61-64.

19. Sutherland IW: Novel and established applications of microbial polysaccharides. Trends Botechnol 1998, 16:41-46.

20. Compere AL, Griffith WL: Production of high viscosity glucan from hydrolyzed cellulosics. Develop Ind Microbiol 1978, 19:601-607.

21. Catley BJ: Utilization of carbon sources by Pullularia pullulan for the elaboration of extracellular polysaccharides. App/Microbio/ 1971, 22:641-645

22. Harada T: Production, properties and applications of curdlan. Am Chem Soc Symp Ser 1977, 45:265-253.

23. Jeanes A: Applications of extracellular microbial polysaccharides polyelectrolytes: review of literature including patents. J Polym Sci 1974, 45:209-227.

24. Holzwarth G: Molecular weight of xanthan polysaccharide. Carbohydr Res 1978, 76:277-280.

25. Clementi F: Alginate production by Azotobacter vinelandii. Crit Rev Biotechnol 1997, 17:327-361.

26. Bae JT, Sinha J, Park JP, Song CH, Yun JW: Optimization of submerged culture condition for Exo-Biopolymer production by Paecilomyces japonica. Microbiol Biotechnol 2000, 10:482-487.

27. Sinha J, Bae JT, Park JP, Kim KH, Song CH, Yun JW: Changes in morphology of Paecilomyces japonica and their effect on broth rheology during production of exo-biopolymers. Appl Microbiol Biotechnol 2001, 56:88-92.

28. Sinha J, Bae JT, Song CH, Yun JW: Effect of substrate concentration on broth rheology and fungal morphology during exobiopolymer production by Paecilomyces japonica in a batch bioreactor. Enz Microb Tech 2001, 29:392-399.

29. Kokub D: Production of biopolymers by indigenous fungal strains of Sclerotium rolfsii and their possible use in petroleum industry. $\mathrm{PhD}$ thesis. Arid Agricultural University Rawalpindi, Pakistan; 2008

30. Peng $Y$, Zhang $L$, Zeng $F, X u Y$ : Structure and antitumor activity of extracellular polysaccharides from mycelium. Carbohydr Polym 2003, 54:297-303

31. McNeely WH, Kang KS: Xanthan and other biosynthetic gums. In Industrial Gums New York: Academic Press; 1973:473-497.

32. Xu CP, Sinha J, Bae JT, Kim SW, Yun JW: Optimization of physical parameters for exo-biopolymer production in submerged mycelial cultures of two entomopathogenic fungi Paecilomyces japonica and Paecilomyces tenuipes. Lett App Microbiol 2006, 42:501-506. 
33. Xu CP, Yun JW: Influence of aeration on the production and the quality of the exopolysaccharides from Paecilomyces tenuipes C240 in a stirredtank fermenter. Enz Microb Tech 2004, 35:33-39.

34. Moreira MT, Sanroman A, Feijoo G, Lema JM: Control of pellet morphology of filamentous fungi in fluidized bed bioreactors by means of a pulsing flow. Application to Aspergillus niger and Phanerochaete chrysosporium. Enz Microb Tech 1996, 19:261-266.

35. Borràs E, Blánquez P, Sarrà M, Caminal G, Vicent T: Trametes versicolor pellets production: Low-cost medium and scale-up. Biochem Eng J 2008, 42:61-66.

36. Li GQ, Qiu HW, Zheng ZM, Cai ZL, Yang SZ: Effect of fluid rheological properties on mass transfer in a bioreactor. J Chem Tech Biotechnol 1995, 62:385-391.

37. López JLC, Pérez JAS, Sevilla JMF, Porcel EMR, Chisti Y: Pellet morphology, culture rheology and lovastatin production in cultures of Aspergillus terreus. J Biotechnol 2005, 116:61-77.

doi: 10.1186/1472-6750-10-51

Cite this article as: Kocharin et al., Exobiopolymer production of Ophiocordyceps dipterigena BCC 2073: optimization, production in bioreactor and characterization BMC Biotechnology 2010, 10:51

Submit your next manuscript to BioMed Central and take full advantage of:

- Convenient online submission

- Thorough peer review

- No space constraints or color figure charges

- Immediate publication on acceptance

- Inclusion in PubMed, CAS, Scopus and Google Scholar

- Research which is freely available for redistribution

Submit your manuscript at www.biomedcentral.com/submit
C Biomed Central 